\title{
Anticancer activity and antioxidant potential of Aponogeton undulatus against Ehrlich ascites carcinoma cells in Swiss albino mice
}

\author{
MOHAMMAD SAIFUR RAHMAN ${ }^{1 *}$, MOHAMMAD BADRUL ALAM $^{2 *}$, YUN HEE CHOI $^{1}$ and JIN CHEOL YOO $^{1}$ \\ ${ }^{1}$ Department of Pharmacy, College of Pharmacy, Chosun University, Gwangju 501-759; \\ ${ }^{2}$ Department of Food Science and Biotechnology, Kyungpook National University, Daegu 702-701, Republic of Korea
}

Received February 2, 2016; Accepted January 31, 2017

DOI: $10.3892 / \mathrm{ol} .2017 .6484$

\begin{abstract}
The in vivo anticancer and in vitro antioxidant effects of the crude methanol extract of Aponogeton undulatus, in addition to its various organic fractions, were investigated. Various assay methods, including the total antioxidant capacity assay, lipid peroxidation inhibition assay, 1,1-diphenyl-2-picrylhydrazyl (DPPH) free radical scavenging assay and ferrous reducing power assessment were used to evaluate the antioxidant potential of the crude extract and its organic fractions. The ethyl acetate fraction (EAU) demonstrated the highest antioxidant capacity (175.80 $\pm 0.41 \mathrm{mg} / \mathrm{g}$ equivalent ascorbic acid), which exhibited $\mathrm{IC}_{50}$ values of DPPH scavenging activity and maximum lipid peroxidation of $38.84 \pm 0.02$ and $42.52 \pm 0.32 \mu \mathrm{g} / \mathrm{ml}$, respectively. The reducing power of the extract was concentration dependent. The in vivo antitumor activity was evaluated against Ehrlich ascites carcinoma (EAC) cell-bearing Swiss albino mice. EAUs (50, 100 and $200 \mathrm{mg} / \mathrm{kg}$ body weight) were administered for nine consecutive days. On day 10 , half of the mice were sacrificed and the remaining mice were evaluated for lifespan. Hematological profiles including, red blood cell, white blood cell and hemoglobin content were also evaluated. EAU treatment significantly $(\mathrm{P}<0.05)$ decreased tumor volume, packed cell volume and viable cell count, and increased the lifespan of EAC tumor-bearing mice. Hematological profiles were restored to normal levels in EAU-treated mice compared with EAC control mice. Taken together, these results suggest that the Aponogeton undulatus extract may have potent antioxidant and anticancer properties.
\end{abstract}

Correspondence to: Professor Jin Cheol Yoo, Department of Pharmacy, College of Pharmacy, Chosun University, 309 Pilmun-daero, Gwangju 501-759, Republic of Korea E-mail: jcyu@chosun.ac.kr

*Contributed equally

Key words: antioxidant, anticancer, Ehrlich ascites carcinoma, Aponogeton undulatus

\section{Introduction}

In addition to numerous types of oxygen-centered free radicals, various physiological and biochemical processes in the human body may produce other reactive oxygen species (ROS) (1). High concentrations of these free radicals may induce oxidative damage to cell structures including lipids and membranes, proteins and nucleic acids; this damage is often referred to as oxidative stress and eventually leads to numerous chronic diseases, including atherosclerosis, cancer, diabetes and other degenerative diseases in humans $(2,3)$. ROS have previously been revealed to be involved in cancer initiation and promotion, and patients with neoplasms demonstrated elevated malondialdehyde (MDA) concentrations (4). Furthermore, evidence indicating that antioxidants inhibit free radical damage suggests that treatment with a combination of antioxidants may be a potent adjunctive preventive treatment for cancer (5).

Phytochemicals are still widely used worldwide and across the major groups of human medicine, presently, they comprise $\sim 50 \%$ of the total pharmaceutical market (6). A number of countries and studies are extracting and investigating potent and nontoxic antioxidants from natural sources, in particular those identified in edible or medicinal plants, in order to prevent free radical-associated human disorders and to replace synthetic compounds, which likely possess carcinogenic activity or activity that is harmful to the lungs and liver (7). For $~ 5,000$ years, thousands of plant species in Bangladesh have demonstrated medicinal value, and various sections of several medicinal plants have been used for the prevention and treatment of complex diseases (6).

Aponogeton undulatus belongs to the family Aponogetonaceae and may be found growing in India, Sri Lanka, Myanmar, Bangladesh and China (8). The rootstock of the plant is an important source of food that may be useful as a nutrient supplement in numerous areas of the world, where purchasing power is limited due to low incomes (9). The rootstock of Aponogeton undulatus may provide an adequate supply of carbohydrates $(42.8 / 100 \mathrm{~g})$, protein $(8.3 / 100 \mathrm{~g})$, fats $(0.7 / 100 \mathrm{~g})$, iron $(18.2 / 100 \mathrm{~g})$, calcium $(37.2 / 100 \mathrm{~g})$ and various additional minerals (9). Additionally, in Ayurvedic medicine, leaf pastes from the plant combined with hot water 
have been used to treat cuts and wounds; the plant has been claimed to be effective against coughs, tuberculosis, acne, cancer, diarrhea, dysentery and jaundice, among other medical problems (10). As reported previously, the primary constituents of Aponogeton undulatus are tannins and alkaloids, which possess thrombolytic and broad-spectrum antibacterial activity, in addition to potential toxicity (11). The present study aimed to evaluate the in vitro antioxidative and in vivo anticancer activity of Aponogeton undulatus leaf extracts, in addition to its organic fractions. To the best of our knowledge, this is the first report investigating the in vivo anticancer activity of Aponogeton undulatus extract against Ehrlich ascites carcinoma (EAC) cells in mice.

\section{Materials and methods}

Plant materials. Aponogeton undulatus leaves were collected from the village Kamatpara in the Panchagarh district of Bangladesh, during August 2009. The leaves were identified by a taxonomist at the National Herbarium of Bangladesh (Mirpur, Dhaka), and its voucher specimen number (32095) has been maintained in our laboratory for future reference.

Chemicals. Folin-chiocaltu phenol reagent was purchased from Merck KGaA (Darmstadt, Germany). In addition, 1,1-diphenyl-2-picryl-hydrazyl (DPPH), ascorbic acid, quercetin, 5,5'-dithiobis (2-nitrobenzoic acid; DTNB), L-2-amino-3-mercapto-3-methylbutanoic acid (L-penicillamine), diethylene triamine pentaacetic acid (DTPA) and potassium ferricyanide, bleomycin, and trichloroacetic acid (TCA) were purchased from Sigma (St. Louis, MO, USA). 6-Hydroxy-2,5,7,8-tetramethylchroman-2-carboxylic acid (Trolox) was purchased from Aldrich Chemical Co. (Milwaukee, WI, USA). Thiobarbituric acid (TBA) and nitroblue tetrazolium chloride (NBT) were purchased from Loba Chemie Pvt., Ltd. (Mumbai, India), and 5,5'-dithio bis-2-nitro benzoic acid (DTNB), phenazine methosulfate (PMS) and nicotinamide adenine dinucleotide (NADH) were supplied by Sisco Research Laboratories Pvt., Ltd. (Mumbai, India). All chemicals and reagents were of the highest analytical grade.

Preparation of crude plant extract. The plant material was shade-dried with occasional shifting, prior to being ground to a powder using a mechanical grinder, passed through sieve no. 40 (particle/mesh; size, $0.420 \mathrm{~mm}$ ) and stored in an airtight container. A total of $\sim 500 \mathrm{~g}$ of the dried, powdered plant material was added to an amber colored extraction bottle (capacity, 2.5 1) and the material was soaked with methanol (extraction performed 3 times; volume, 1.01 each time). The sealed bottle containing plant material and methanol was stored for seven days at room temperature (RT; $\left.37^{\circ} \mathrm{C}\right)$ with occasional shaking and stirring. The combined extracts were filtered through cotton and subsequently Whatman No. 1 filter papers, prior to being concentrated with a rotary evaporator under reduced pressure at $45^{\circ} \mathrm{C}$ until dry in vacuo, to provide $40 \mathrm{~g}$ crude methanol extract of Aponogeton undulatus leaves (MAU). The extract was suspended with $100 \mathrm{ml}$ of water at RT for $2 \mathrm{~h}$ (fractionation for $2 \mathrm{~h}$ at RT), followed by fractionated by chloroform, and ethyl acetate (in each $100 \mathrm{ml}$ ) to obtain the chloroform fraction (CAU; $5.08 \mathrm{~g})$, ethyl acetate fraction (EAU; $10.18 \mathrm{~g}$ ) and finally aqueous fraction (WAU; $9.15 \mathrm{~g}$ ).

\section{In vitro antioxidant activity}

Determination of total phenol. Total phenolic content of the extracts was determined by the modified Folin-Ciocalteu method previously described by Yu et al (12). An aliquot of the extracts/standard was mixed with $2 \mathrm{ml}$ Folin-Ciocalteu reagent (Sigma-Aldrich; Merck KGaA; previously diluted with water $1: 10 \mathrm{v} / \mathrm{v})$ and $2 \mathrm{ml}(75 \mathrm{~g} / \mathrm{l})$ sodium carbonate. Tubes were vortexed at 1,000 x g for $15 \mathrm{sec}$ and allowed to stand for $20 \mathrm{~min}$ at $25^{\circ} \mathrm{C}$, for color development. Absorbance was subsequently determined at $760 \mathrm{~nm}$ with a UV-spectrophotometer (Shimadzu Corporation, Kyoto, Japan). Samples of extracts/standard were evaluated at a final concentration of $0.1 \mathrm{mg} / \mathrm{ml}$. Total phenolic content was expressed in terms of the gallic acid equivalent (GAE; standard curve equation: $\mathrm{y}=0.011 \mathrm{x}+0.066, \mathrm{R}^{2}=0.998$ ), mg GAE/g of dry extract.

Determination of total flavonoid content. Total flavonoid content was determined using the method as previously described by Chang et al (13). To a total of $0.5 \mathrm{ml}$ of samples/standard, $1.5 \mathrm{ml}$ methanol, $100 \mu 110 \%$ aluminum chloride, $100 \mu 11 \mathrm{M}$ potassium acetate solution and $2.8 \mathrm{ml}$ distilled water were added. Following a 90-min incubation at RT, the absorbance was evaluated at $420 \mathrm{~nm}$ using UV-spectrophotometer (Shimadzu Corporation). The samples and standard were observed at a final concentration of $0.1 \mathrm{mg} / \mathrm{ml}$. Total flavonoid content was expressed in terms of the quercetin equivalent (QAE; standard curve equation: $\left.\mathrm{y}=0.003 \mathrm{x}+0.022, \mathrm{R}^{2}=0.997\right), \mathrm{mg}$ of QAE/g of dry extract.

Determination of total flavonol content. Total flavonol content in the plant extracts was determined using the method previously described by Kumaran and Karunakaran (14). To $2.0 \mathrm{ml}$

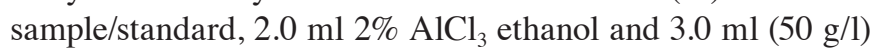
sodium acetate solutions were mixed together and stand for complete the reaction at $20^{\circ} \mathrm{C}$ for $1 \mathrm{~h}$, followed by the absorption was measured at $440 \mathrm{~nm}$ using a spectrophotometer (Shimadzu, Tokyo, Japan). Extracts and the standard were evaluated at a final concentration of $0.1 \mathrm{mg} / \mathrm{ml}$. The total content of flavonols was expressed in terms of QAE (standard curve equation: $\left.y=0.0255 x+0.0069, R^{2}=0.9995\right), \mathrm{mg}$ of $\mathrm{QAE} / \mathrm{g}$ of dry extract.

Determination of total antioxidant capacity (TAC). The TAC of samples/standard was determined using the method previously described by Prieto et al (15), with partial modifications as follows. A total of $0.5 \mathrm{ml}$ of the extract/fractions $(200 \mu \mathrm{g})$ and the standard at various concentrations $(0,25,50,75$, $100,125,150$ and $200 \mu \mathrm{g} / \mathrm{ml}$ ) were mixed with $3 \mathrm{ml}$ reaction mixture in test tubes, which contained, 0.6 M sulfuric acid, $28 \mathrm{mM}$ sodium phosphate and $1 \%$ ammonium molybdate. The test tubes were incubated at $95^{\circ} \mathrm{C}$ for $10 \mathrm{~min}$ in order to complete the reaction. Following cooling at RT (30 min), the absorbance was determined at $695 \mathrm{~nm}$ using a spectrophotometer (Shimadzu, Tokyo, Japan) against a blank. Ascorbic acid was used as the standard. A typical blank solution contained $3 \mathrm{ml}$ reaction mixture and the appropriate volume of the same solvent used for the samples/standard, and it was incubated 
at $95^{\circ} \mathrm{C}$ for $10 \mathrm{~min}$ prior to the absorbance being evaluated at $695 \mathrm{~nm}$. Increased absorbance of the reaction mixture indicated an increase in the total antioxidant capacity of Aponogeton undulatus.

DPPH free radical scavenging assay. A solution of $0.1 \mathrm{mM}$ DPPH in methanol was prepared and $2.4 \mathrm{ml}$ of the solution was mixed with $1.6 \mathrm{ml}$ of each extract/fractions at various concentrations $(10-160 \mu \mathrm{g} / \mathrm{ml})$. The reaction mixture was vortexed thoroughly $(1,000 \mathrm{x} \mathrm{g})$ and left in the dark at RT for $30 \mathrm{~min}$. The absorbance of the mixture was evaluated spectrophotometrically at $517 \mathrm{~nm}$. Ascorbic acid was used as a reference standard. Percentage of DPPH radical scavenging activity was calculated by the following equation:

$$
\% \mathrm{DPPH} \text { radical scavenging activity }=\left[\left(\mathrm{A}_{0}-\mathrm{A}_{1}\right) / \mathrm{A}_{0}\right] \times 100
$$

$A_{0}$ is the absorbance of the control and $A_{1}$ is the absorbance of the extractives/standard. Subsequently, the percentage of inhibition was plotted against concentration, and from the graph the $\mathrm{IC}_{50}$ was determined (16).

Lipid peroxidation inhibition assay. The lipid peroxidation inhibition assay was determined according to the method previously described by Liu and $\mathrm{Ng}$ (17). Briefly, excised rat liver (surgically removed from healthy rats) was homogenized in PBS and centrifuged at $20,000 \mathrm{x}$ g for $15 \mathrm{~min}$ at $4^{\circ} \mathrm{C}$ to obtain liposomes. In total, $0.5 \mathrm{ml}$ supernatant, $100 \mu 110 \mathrm{mM}$ $\mathrm{FeSO}_{4}, 100 \mu \mathrm{l} 0.1 \mathrm{mM}$ AA and $0.3 \mathrm{ml}$ extractives/standard at various concentrations $(10,20,40,80$ and $160 \mu \mathrm{g} / \mathrm{ml})$ were mixed together to make the final volume of $1 \mathrm{ml}$. The reaction mixture was incubated at $37^{\circ} \mathrm{C}$ for $20 \mathrm{~min}$. A total of $1 \mathrm{ml}$ (28\%) TCA and $1.5 \mathrm{ml}(1 \%)$ TBA were added immediately subsequent to heating $\left(100^{\circ} \mathrm{C}\right)$. Finally, the reaction mixture was heated again at $100^{\circ} \mathrm{C}$ for $15 \mathrm{~min}$ and cooled at RT for 30 min. Following cooling, the absorbance was determined at $532 \mathrm{~nm}$. Percentage of inhibition of lipid peroxidation was determined using the following equation:

$$
\% \text { lipid peroxidation inhibition }=\left[\left(\mathrm{A}_{0}-\mathrm{A}_{1}\right) / \mathrm{A}_{0}\right] \times 100
$$

Subsequently, the percent of inhibition was plotted against concentration, and using the graph, the $\mathrm{IC}_{50}$ was evaluated.

Determination of ferrous reducing antioxidant capacity. The reducing power of Aponogeton undulatus leaf extract was determined according to the previously described study by Oyaizu (18). Briefly, $0.25 \mathrm{ml}$ samples/standard solution at different concentrations $(10,20,40,80$ and $160 \mu \mathrm{g} / \mathrm{ml})$ $0.625 \mathrm{ml}$ potassium buffer $(0.2 \mathrm{M})$ and $0.625 \mathrm{ml} 1 \%$ potassium ferricyanide $\left[\mathrm{K}_{3} \mathrm{Fe}(\mathrm{CN})_{6}\right]$ solution was added to the test tubes. The reaction mixture was incubated for $20 \mathrm{~min}$ at $50^{\circ} \mathrm{C}$ to complete the reaction. Subsequently, $0.625 \mathrm{ml} 10 \%$ TCA solution was added to the test tubes. The total mixture was centrifuged at 3,000 x $\mathrm{g}$ for $10 \mathrm{~min}$ at RT. Following this, $1.8 \mathrm{ml}$ supernatant was withdrawn from the test tubes and was mixed with $1.8 \mathrm{ml}$ distilled water and $0.36 \mathrm{ml} 0.1 \% \mathrm{FeCl}_{3}$ solution. The absorbance of the solution was evaluated at $700 \mathrm{~nm}$ using a spectrophotometer (Shimadzu Corporation) against a blank. A typical blank solution containing the same solution mixture without plant extracts/standard was also incubated under the same conditions, and the absorbance of the blank solution was evaluated at $700 \mathrm{~nm}$. Increased absorbance of the reaction mixture indicates increased reducing capacity.

\section{In vivo anticancer activity}

Animals. A total of 60, 6-7-week-old, Swiss albino mice (weight range, 25-30 g) of both genders (Samtako Bio Korea, Osan, Korea), were divided into six groups, each consisting of 12 animals, and were used to assess biological activity. Animals were maintained in an air-conditioned room at a temperature of $22 \pm 1^{\circ} \mathrm{C}$ and a humidity of $55 \pm 1 \%$ with a $12 \mathrm{~h}$ light/dark cycle. They were fed a standard commercial rodent pellet diet (Samtako Bio Korea), and had ad libitum access to water. The animals were allowed to acclimate to the environment for seven days prior to the experimental session. All animal experiments were performed in accordance with the guidelines of the Institutional Animal Ethics Committee, Atish Dipankar University of Science \& Technology (Dhaka, Bangladesh). Animal treatment and maintenance for acute toxicity and effects were strictly followed in accordance with the Principle of Laboratory Animal Care (19) and the Animal Care and Use Guidelines of Atish Dipankar University of Science \& Technology.

Acute toxicity study. A total of 30, 6-7-week-old, Swiss albino mice (weight range, 25-30 g) of both genders (Samtako Bio Korea), were divided into five groups $(n=6)$, and were used to assess acute toxicity activity. The test was performed using increasing oral doses of EAU in distilled water (50, 100, 200, 500 and $1,000 \mathrm{mg} / \mathrm{kg}$ body weight) that were administered orally at $20 \mathrm{ml} / \mathrm{kg}$ to each test group. The normal control group received distilled water $(1 \mathrm{ml})$. Following treatment, mice were allowed to feed ad libitum and observed for $48 \mathrm{~h}$ for any mortality or behavioral changes (20).

Transplantation of cancer cells. EAC cells were acquired from Professor M. Ekramul Haque (Department of Pharmacy, Rajshahi University, Rajshahi, Bangladesh). The EAC cells were maintained in vivo in Swiss albino mice by intraperitoneal transplantation of $2 \times 10^{6}$ cells suspended in PBS per mouse every 10 days. Ascitic fluid was drawn from EAC cell-bearing mice at the log phase (days 7-8 of tumor bearing) of the cancer cell growth, and each test animal received $0.1 \mathrm{ml}$ cancer cell suspension containing $2 \times 10^{6}$ cells intraperitoneally (i.p.) (21).

Treatment schedule. Mice were divided into six groups $(\mathrm{n}=12)$ and provided with food and water ad libitum. All animals in each group received EAC cells $\left(2 \times 10^{6}\right.$ cells/mouse, i.p. $)$ except group I, which served as the normal saline control (5 $\mathrm{ml} / \mathrm{kg}$ body weight i.p.). Group II served as the EAC control. Following a 24-h period post-EAC transplantation, group VI received bleomycin 0.3 (i.p.) $\mathrm{mg} / \mathrm{kg}$ body weight (positive control), and groups III, IV and V were treated with 50, 100 and $200 \mathrm{mg} / \mathrm{kg}$ body weight (p.o.) EAU, respectively, for nine consecutive days. Following $24 \mathrm{~h}$ from the last dose, the animals were fasted for $18 \mathrm{~h}$; six animals in each group were subsequently sacrificed by cardiac puncture to estimate hematological parameters, as well as to determine anticancer activity. The remaining mice were provided with food and 
water ad libitum and observed to determine if there were any changes in lifespan. The anticancer activity of the extract was evaluated in EAC animals.

Determination of tumor and packed cell volume (PVC). Mice were dissected and ascetic fluid was collected from the peritoneal cavity. Volume was determined using a graduated conical centrifuge tube, following which the PCV was determined by centrifuging the fluid at $1,000 \mathrm{xg}$ at $4^{\circ} \mathrm{C}$ for $5 \mathrm{~min}$.

Viable and nonviable cancer cell count. Ascetic fluid was collected in a white blood cell (WBC) pipette and diluted 100 times using PBS. A drop of the diluted suspension was subsequently placed on a Neubauer counting chamber, and the cells were stained with trypan blue ( $0.4 \%$ in normal saline). Cells that did not take up the dye were considered viable, whereas those that did were considered non-viable. These viable and non-viable cells were counted using the following equation:

\section{Cell count $=($ number of cells $\mathrm{x}$ dilution factor $) /($ area $\mathrm{x}$ thickness of liquid film)}

Determination of median survival time and percentage increase in lifespan. Mortality was monitored by recording the percentage increase in lifespan (\% ILS) and the median survival time (MST), according to the following formula (22):

$$
\% \mathrm{ILS}=\left(\frac{\text { Mean survival time of the treated group }}{\text { Mean survival time of the control group }}-1\right) \times 100
$$

Where mean survival time ${ }^{*}=$ (day of first mortality + day of last mortality)/2; ("time is denoted by the number of days).

Estimation of hematological parameters. Collected blood was used to estimate the hemoglobin $(\mathrm{Hb})$ content, red blood cell (RBC) and WBC count. Differential counts of WBC were performed using Leishman stained blood smears (23).

Statistical analysis. All values are expressed as the mean \pm standard error of the mean of three replicated experiments. The analysis was performed using SPSS statistical package for WINDOWS (version 16.0; SPSS, Inc., Chicago, IL, USA). Results associated with the reducing power activities were statistically analyzed by applying the Student's t-test, and $\mathrm{P}<0.001$ was considered to indicate a statistically significant difference. All in vivo data were subjected to analysis of variance followed by Dunnett's test, and $\mathrm{P}<0.05$ was considered to indicate a statistically significant difference.

\section{Results}

\section{In vitro antioxidant activity}

Total phenolic, flavonoid and flavonol contents. As presented in Table I, the total extractable phenolic content of the Aponogeton undulatus fractions was calculated to be $95.24 \pm 0.42$ in the MAU, $24.57 \pm 1.02$ in the CAU, $134.29 \pm 1.12$ in the EAU and $41.29 \pm 0.22$ in the WAU, all of which are expressed as GAE (mg/g of each extract). The flavonoid content in the fractions was determined to be $129.40 \pm 0.21$ in the MAU, 28.40 \pm 0.61 in the CAU, 205.40 \pm 0.31 in the EAU and $70.20 \pm 0.41$ in the WAU, all of which are expressed as
QAE (mg/g of each extract). Total flavonol contents were $46.40 \pm 0.11$ in the MAU, $71.47 \pm 0.31$ in the CAU, $57.80 \pm 0.51$ in the EAU and $16.00 \pm 0.21$ in the WAU, all of which are expressed in terms of QAE. There was an association between the extract phenolic content, the DPPH radical scavenging activity and lipid peroxidation inhibition activity with linear correlation coefficients. $\mathrm{R}^{2}=0.9559$ in $\mathrm{MAU}, \mathrm{R}^{2}=0.9633$ in CAU, $\mathrm{R}^{2}=0.8474$ in EAU and $\mathrm{R}^{2}=0.8991$ in WAU for phenolic content and DPPH-radical scavenging activity (Fig. 1A) and $\mathrm{R}^{2}=0.8419$ in $\mathrm{MAU}, \mathrm{R}^{2}=0.9455$ in $\mathrm{CAU}, \mathrm{R}^{2}=0.8467$ in $\mathrm{EAU}$ and $\mathrm{R}^{2}=0.9108$ in WAU for phenolic content and lipid peroxidation inhibition activity (Fig. 1B).

Total antioxidant capacity. The total antioxidant capacity of various organic soluble fractions of Aponogeton undulatus leaf extract were expressed as the number of equivalents of ascorbic acid (Table I). The total antioxidant capacity of EAU was the highest of all the fractions and was revealed to be $175.80 \pm 0.41 \mathrm{mg} / \mathrm{g}$, followed by MAU, WAU and CAU, which displayed antioxidant capacities of $109.20 \pm 0.41,54.20 \pm 0.81$ and $32.80 \pm 0.11 \mathrm{mg} / \mathrm{g}$ equivalent of ascorbic acid, respectively.

DPPH free radical scavenging assay. All Aponogeton undulatus fractions exhibited H-donor activity. EAU demonstrated the highest DPPH scavenging activity with an $\mathrm{IC}_{50}$ value of $38.84 \pm 0.02 \mu \mathrm{g} / \mathrm{ml}$, followed by MAU and WAU, which had $\mathrm{IC}_{50}$ values of $75.24 \pm 0.56$ and $137.63 \pm 0.12 \mu \mathrm{g} / \mathrm{ml}$, respectively (Table II). CAU exhibited no activity within the experimental concentration range.

Lipid peroxidation inhibition assay. The lipid peroxide scavenging activity of the Aponogeton undulatus fractions was investigated and compared to the standard ascorbic acid. The $\mathrm{IC}_{50}$ values of MAU, CAU, EAU and WAU were $49.11 \pm 0.41$, $138.38 \pm 0.61,42.52 \pm 0.32$ and $113.98 \pm 0.33 \mu \mathrm{g} / \mathrm{ml}$, respectively (Table II). By contrast, the $\mathrm{IC}_{50}$ value of standard ascorbic acid was $38.52 \pm 0.12 \mu \mathrm{g} / \mathrm{ml}$.

Ferrous reducing antioxidant capacity. Reductive ability was determined by evaluating the transformation of $\mathrm{Fe}_{3+}$ to $\mathrm{Fe}_{2+}$ in the presence of Aponogeton undulatus leaf extract and its various organic fractions. Fig. 2 depicts the reductive capabilities of the Aponogeton undulatus leaf extract fractions, which exhibited dose-dependent activity compared with the commercial ascorbic acid and quercetin.

\section{In vivo anticancer activity}

Acute toxicity studies. Acute toxicity studies primarily aim to establish the therapeutic index (the ratio between the pharmacologically effective dose and the lethal dose) within the same strain and species (20). EAU was safe at doses as high as $1,000 \mathrm{mg} / \mathrm{kg}$ (p.o.) body weight. The behavior of the animals was closely observed for the first $3 \mathrm{~h}$, then every $4 \mathrm{~h}$ during the next 48 -h period. The extract did not induce mortality, behavioral changes, locomotor ataxia, diarrhea or weight loss in mice during the $48-\mathrm{h}$ observation period. Furthermore, food and water intake did not differ among the groups studied.

Cell growth and survival parameters. EAU (200 mg/kg body weight) administration significantly reduced tumor volume, 
Table I. Total quantity of phenols, flavonoids and flavonols and the total antioxidant capacity of various organic soluble fractions of Aponogeton undulatus leaves.

\begin{tabular}{lcccc}
\hline Sample & $\begin{array}{c}{ }^{\mathrm{a}} \text { Total phenols mg/g } \\
\text { plant extract (in GAE) }\end{array}$ & $\begin{array}{c}\text { b Total flavonoids mg/g } \\
\text { plant extract (in QAE) }\end{array}$ & $\begin{array}{c}{ }^{\mathrm{b}} \text { Total flavonols mg/g } \\
\text { plant extract (in QAE) }\end{array}$ & $\begin{array}{c}{ }^{\mathrm{c} T o t a l ~ a n t i o x i d a n t ~ c a p a c i t y ~ m g / g ~} \\
\text { plant extract (in ASC) }\end{array}$ \\
\hline MAU & $95.24 \pm 0.42$ & $129.40 \pm 0.21$ & $46.40 \pm 0.11$ & $109.20 \pm 0.41$ \\
CAU & $24.57 \pm 1.02$ & $28.40 \pm 0.61$ & $71.47 \pm 0.31$ & $32.80 \pm 0.11$ \\
EAU & $134.29 \pm 1.12$ & $205.40 \pm 0.31$ & $57.80 \pm 0.51$ & $175.80 \pm 0.41$ \\
WAU & $41.29 \pm 0.22$ & $70.20 \pm 0.41$ & $16.00 \pm 0.21$ & $54.20 \pm 0.81$ \\
\hline
\end{tabular}

The GAE, QAE and ASC values are expressed as the mean \pm standard error of the mean of triplicate experiments. ${ }^{\mathrm{a}} \mathrm{GAE}$ (mg/g of each extract) for the total phenolic content. ${ }^{\mathrm{b}} \mathrm{QAE}\left(\mathrm{mg} / \mathrm{g}\right.$ of each extract) for the total flavonoid and flavonol content. ${ }^{\mathrm{c}} \mathrm{ASC}$ (mg/g of each extract) for the total antioxidant capacity. GAE, gallic acid equivalents; QAF, quercetin equivalent; ASC, ascorbic acid equivalent; MAU, methanol extract of Aponogeton undulatus; CAU, chloroform fraction of Aponogeton undulatus; EAU, ethylacetate fraction of Aponogeton undulatus; WAU, water fraction of Aponogeton undulatus.

A

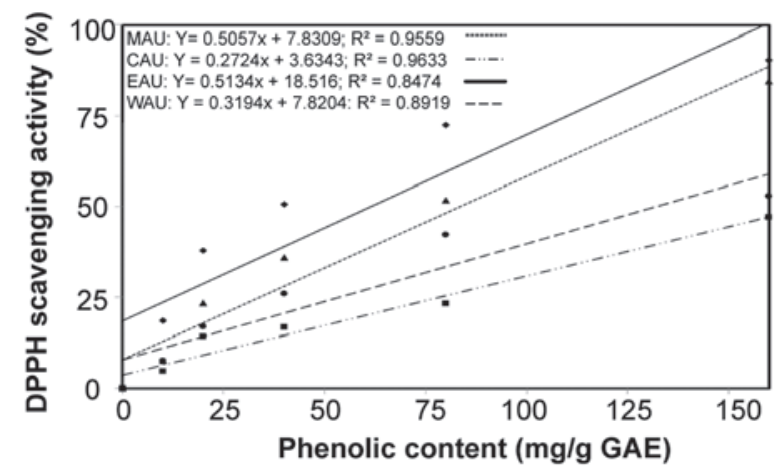

B

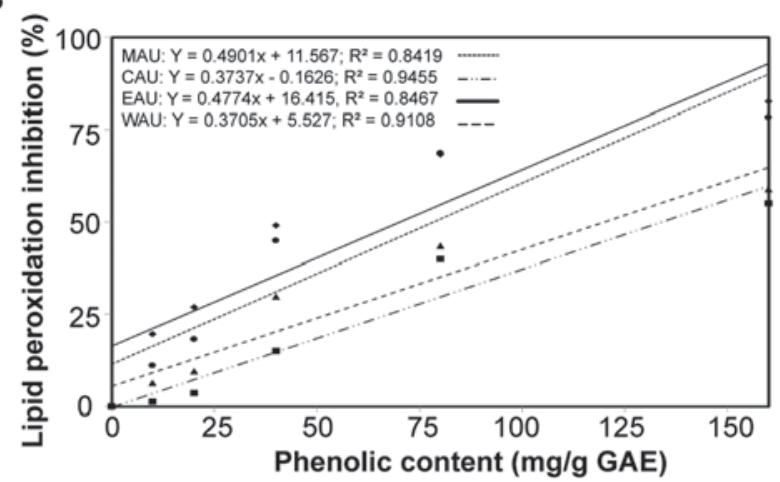

Figure 1. (A) Correlation between phenolic content and DPPH scavenging activity. (B) Lipid peroxidation inhibition. DPPH, 1,1-diphenyl-2-picrylhydrazyl; GAE, gallic acid equivalent; MAU, methanol extract of Aponogeton undulatus; CAU, chloroform fraction of Aponogeton undulatus; EAU, ethyl acetate fraction of Aponogeton undulatus; WAU, water fraction of Aponogeton undulatus.

PCV (Fig. 3) and the viable cancer cell count; however, it increased the non-viable cancer cell count relative to the EAC control group (data not presented). MST significantly $(\mathrm{P}<0.05)$ increased to $22.61 \pm 0.21$ (\% ILS=18.22), 32.58 \pm 0.31 (\% ILS=45.32) and 36.51 $\pm 0.19(\%$ ILS=65.59) upon administration of EAU at doses of 50, 100 and $200 \mathrm{mg} / \mathrm{kg}$ body weight, respectively, whereas the EAC control $\left(2 \times 10^{6}\right.$ cells/mouse $)$ and the reference drug bleomycin demonstrated survival times of $21.11 \pm 0.12$ and $40.11 \pm 0.11$ (\% ILS=90.00), respectively
Table II. Scavenging/inhibitory effects of various organic soluble fractions of Aponogeton undulatus leaves against DPPH scavenging and lipid peroxide inhibition.

\begin{tabular}{lcc}
\hline Sample & $\begin{array}{c}\mathrm{DPPH} \mathrm{IC}_{50} \\
(\mu \mathrm{g} / \mathrm{ml})\end{array}$ & $\begin{array}{c}\text { Lipid peroxide } \mathrm{IC}_{50} \\
(\mu \mathrm{g} / \mathrm{ml})\end{array}$ \\
\hline MAU & $75.24 \pm 0.56$ & $49.11 \pm 0.41$ \\
CAU & $>160$ & $138.38 \pm 0.61$ \\
EAU & $38.84 \pm 0.02$ & $42.52 \pm 0.32$ \\
WAU & $137.63 \pm 0.12$ & $113.98 \pm 0.33$ \\
Ascorbic acid & $18.84 \pm 0.02$ & $38.52 \pm 0.12$ \\
\hline
\end{tabular}

$\mathrm{IC}_{50}$ values are expressed as the mean \pm standard error of the mean $(\mathrm{n}=3)$. MAU, methanol extract of Aponogeton undulatus; CAU, chloroform fraction of Aponogeton undulatus; EAU, ethylacetate fraction of Aponogeton undulatus; WAU, water fraction of Aponogeton undulatus; DPPH, 1,1-diphenyl-2-picrylhydrazyl.

(Fig. 3). Finally, the animals' changes in body weight (data not presented) suggest that EAU may have the potential to inhibit tumor growth.

Hematological parameters. The hematological parameters of tumor-bearing mice were observed to be significantly $(\mathrm{P}<0.05)$ altered, relative to the normal group (Table III). The total WBC count was revealed to be increased $(\mathrm{P}<0.05)$, whereas a reduction in hemoglobin $(\mathrm{Hb})$ content and $\mathrm{RBC}$ count in the EAC control mice compared with the normal saline group, was observed. Additionally, neutrophils (Fig. 4A) and lymphocytes (Fig. 4B) were observed to decrease, while monocytes (Fig. 4C) increased in the EAC control group, compared with in the normal saline group. Treatment with EAU $(200 \mathrm{mg} / \mathrm{kg}$ body weight, p.o.) significantly $(\mathrm{P}<0.05)$ changed these parameters to near normal values (Fig. 4).

\section{Discussion}

Plants contain free radical scavengers, including phenolic compounds, flavonoids and flavonols, which possess 
Table III. Effect of the EAU on hematological parameters in EAC-bearing mice.

\begin{tabular}{lccc}
\hline Group & Hb content $(\mathrm{g} \%)$ & RBC $\left(\right.$ cells $\left.\times 10^{6} / \mathrm{mm}^{3}\right)$ & WBC $\left(\right.$ cells $\left.\times 10^{6} / \mathrm{mm}^{3}\right)$ \\
\hline Normal saline $(5 \mathrm{ml} / \mathrm{kg})$ & $11.52 \pm 0.76$ & $5.22 \pm 0.19$ & $4.23 \pm 0.21$ \\
EAC control $\left(2 \times 10^{6}\right.$ cell/mouse $)$ & $4.31 \pm 0.56^{\mathrm{a}}$ & $2.11 \pm 0.26^{\mathrm{a}}$ & $7.02 \pm 0.23^{\mathrm{a}}$ \\
EAC + EAU $(25 \mathrm{mg} / \mathrm{kg})$ & $5.21 \pm 0.13^{\mathrm{b}}$ & $2.32 \pm 0.15$ & $6.03 \pm 0.45^{\mathrm{b}}$ \\
EAC + EAU $(50 \mathrm{mg} / \mathrm{kg})$ & $7.12 \pm 0.21^{\mathrm{b}}$ & $3.32 \pm 0.21^{\mathrm{b}}$ & $5.35 \pm 0.52^{\mathrm{b}}$ \\
EAC + EAU $(100 \mathrm{mg} / \mathrm{kg})$ & $9.10 \pm 0.23^{\mathrm{b}}$ & $4.85 \pm 0.22^{\mathrm{b}}$ & $4.62 \pm 0.15$ \\
Bleomycin $(0.3 \mathrm{mg} / \mathrm{kg})$ & $10.82 \pm 0.61^{\mathrm{b}}$ & $4.92 \pm 0.17^{\mathrm{b}}$ & $4.51 \pm 0.24^{\mathrm{b}}$ \\
\hline
\end{tabular}

Each point represents the mean \pm standard error of the mean from triplicate determinations. ( $\mathrm{n}=6$ mice per group), ${ }^{\mathrm{a}} \mathrm{P}<0.05$ was considered to indicate a statistically significant difference compared to the normal saline group. ${ }^{b} \mathrm{P}<0.05$ was considered to indicate a statistically significant difference compared to the EAC control group. MAU, methanol extract of Aponogeton undulatus leaves; EAC, Ehrlich ascites carcinoma; EAU, ethyl acetate fraction of Aponogeton undulatus; Hb, hemoglobin; RBC, red blood cell; WBC, white blood cell.

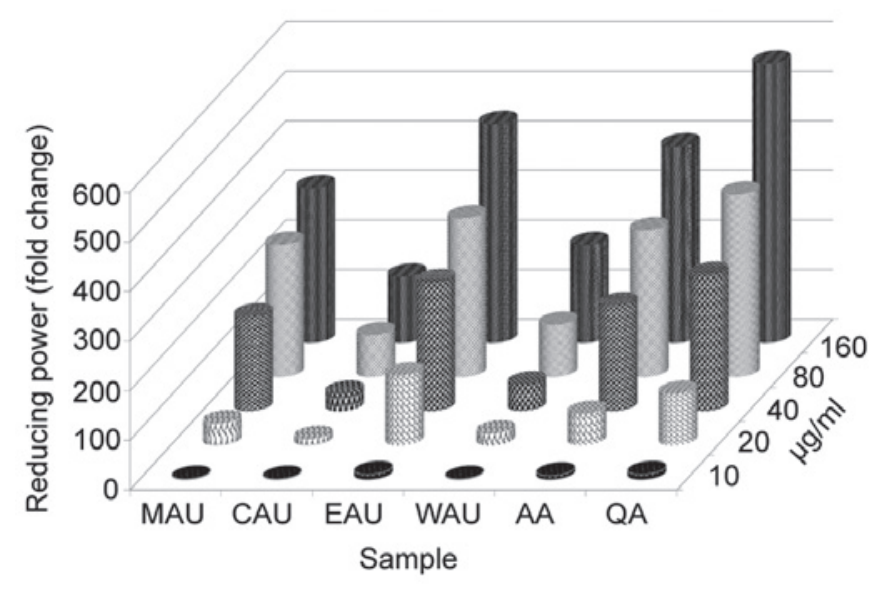

Figure 2. Reducing the activity of Aponogeton undulatus leaf extract and its various organic fractions. AA and QA were used as a standard for comparison. MAU, methanol extract of Aponogeton undulatus; CAU, chloroform fraction of Aponogeton undulatus; EAU, ethyl acetate fraction of Aponogeton undulatus; WAU, water fraction of Aponogeton undulatus; AA, ascorbic acid; QA, quercetin.

antioxidant and anticancer activities (5). The active constituents of these compounds may be isolated and then used as antioxidants for the prevention and treatment of free radical-associated disorders (24). In the present study, MAU and its various organic fractions were investigated for their in vitro antioxidant activity, and only EAU was evaluated for its in vivo anticancer activity against EAC cells in Swiss albino mice.

Phenolic compounds are considered to be secondary metabolites, which are derived from phenylalanine and tyrosine; they occur ubiquitously in plants and are widely distributed (25). However, flavonoids are often identified as glycosylated forms of polyphenolic compounds, exhibiting a distinct molecular structure in plants (24). Differentiating the position of the hydroxyl groups within the phenyl ring significantly alters the characteristics of solubility of the compounds (14). The present study identified that EAU demonstrated the highest antioxidant activity, with $175.80 \pm 0.41 \mathrm{mg} / \mathrm{g}$ plant extract (in ASC) of Aponogeton undulatus. The total content of phenols, flavonoids and flavonols in the Aponogeton undulatus fraction isolates were ordered as follows: EAU> MAU> WAU> CAU (Table I).

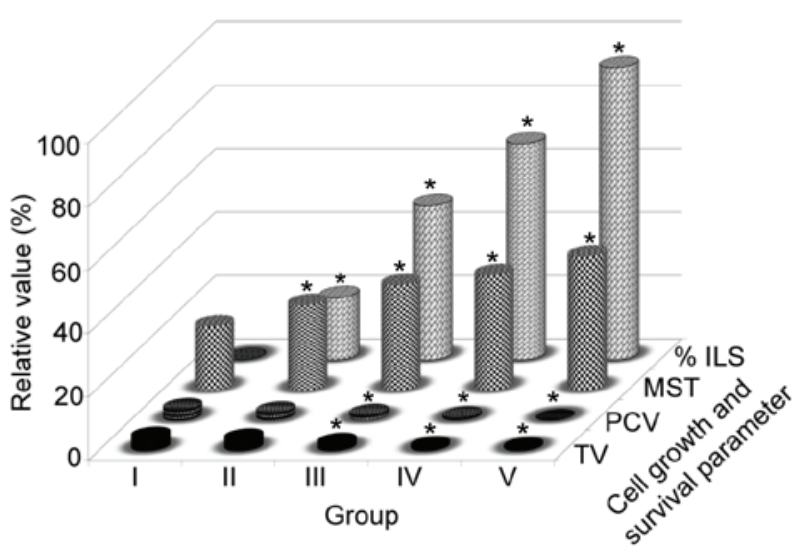

Figure 3. Effects of Aponogeton undulatus leaf extracts on TV,PCV, MST and $\%$ ILS in EAC-bearing mice. Each point represents the mean \pm standard error of the mean from triplicate determinations. ( $\mathrm{n}=6$ mice per group), ${ }^{*} \mathrm{P}<0.05$ was considered statistically significant compared to the EAC control group, Group I animals received EAC control ( $2 \times 10^{6}$ cell/mouse), Group V received bleomycin $(0.3 \mathrm{mg} / \mathrm{kg}$ body weight), and groups II, III and IV, were treated with 50,100 and $200 \mathrm{mg} / \mathrm{kg}$ body weight (p.o.) of the EAU, respectively. TV, tumor volume; PCV, packed cell volume; MST, mean survival time; \% ILS, percentage increase in lifespan; EAC, Ehrlich ascites carcinoma; EAU, ethyl acetate fraction of Aponogeton undulatus.

EAU demonstrated the highest DPPH scavenging effects and lipid peroxidation inhibition, and these effects were dose-dependent (data not presented). The $\mathrm{IC}_{50}$ values of these effects were $38.84 \pm 0.02$ and $42.52 \pm 0.32 \mu \mathrm{g} / \mathrm{ml}$, respectively, while the standard ascorbic acid activity was identified to be $\mathrm{IC}_{50}=18.84 \pm 0.02$ and $\mathrm{IC}_{50}=38.52 \pm 0.12 \mu \mathrm{g} / \mathrm{ml}$, respectively (Table II). There was an association between the extract phenolic content and the DPPH radical scavenging activity linear correlation coefficient: $\mathrm{R}^{2}=0.9559$ in $\mathrm{MAU}, \mathrm{R}^{2}=0.9633$ in $\mathrm{CAU}$, $\mathrm{R}^{2}=0.8474$ in EAU and $\mathrm{R}^{2}=0.8991$ in WAU. Peroxidation of the lipid is a natural phenomenon that occurs on its exposure to oxygen (14). Recently, free radical-induced lipid peroxidation has gained attention due to its involvement in numerous pathological conditions, including aging, wound healing, oxygen toxicity, liver disorders and inflammation (1). The results of the present study revealed that Aponogeton undulatus extracts inhibit lipid peroxidation in a dose-dependent manner (data 
A

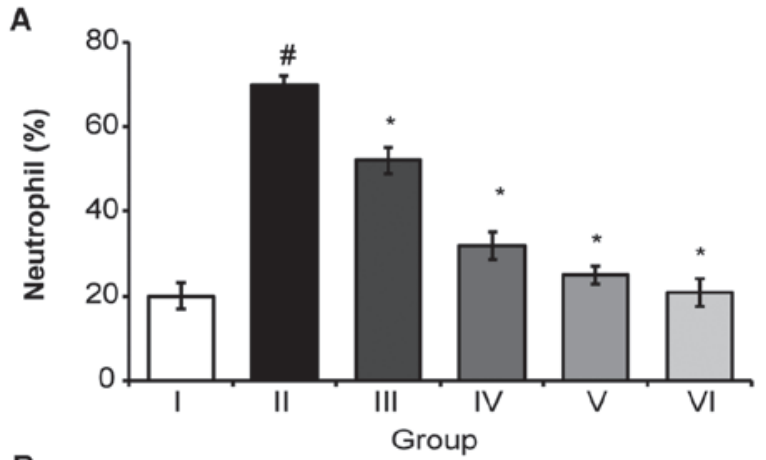

B

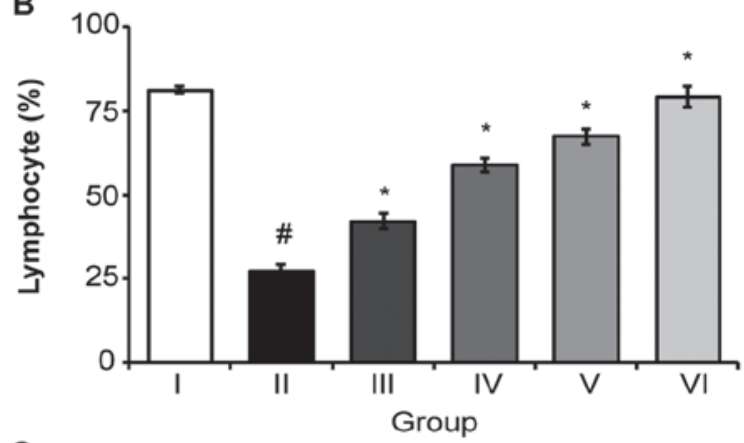

C

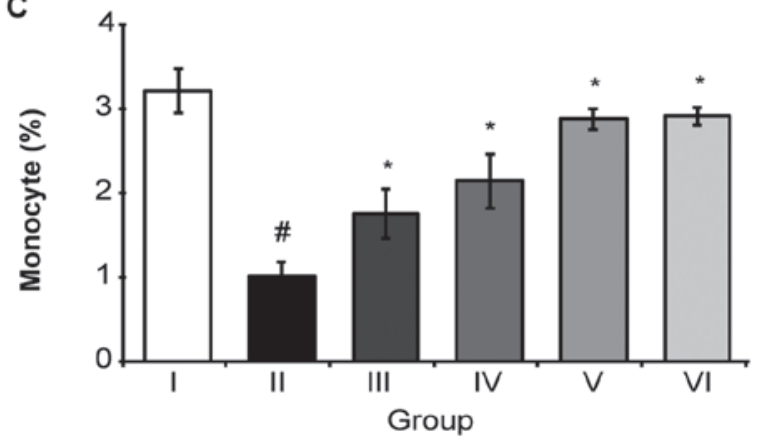

Figure 4. A classical feature of Aponogeton undulatus leaf extracts on differential counts of WBC, (A) neutrophils, (B) lymphocytes and (C) monocytes. Each point represents the mean \pm standard error of the mean from triplicate determinations. ( $\mathrm{n}=6$ mice per group), ${ }^{\#} \mathrm{P}<0.05$ was considered to indicate a statistically significant difference compared to the normal saline group. ${ }^{*} \mathrm{P}<0.05$ was considered to indicate a statistically significant difference compared to the EAC control group. Group I animals received normal saline $(5 \mathrm{ml} / \mathrm{kg})$ whereas group II received EAC control $\left(2 \times 10^{6}\right.$ cell/mouse), Group VI received bleomycin ( $0.3 \mathrm{mg} / \mathrm{kg}$ body weight), and groups III, IV and $\mathrm{V}$ were treated with 25,50 and $100 \mathrm{mg} / \mathrm{kg}$ body weight (p.o.) of the EAU, respectively. WBC, white blood cell; EAC, Ehrlich ascites carcinoma; EAU, ethyl acetate fraction of Aponogeton undulatus leaves.

not presented), and produce a strong and significant correlation between their total phenol content and lipid peroxidation: $\mathrm{R}^{2}=0.8419$ in MAU, $\mathrm{R}^{2}=0.9455$ in $\mathrm{CAU}, \mathrm{R}^{2}=0.8467$ in $\mathrm{EAU}$ and $\mathrm{R}^{2}=0.9108$ in WAU. Phenolic compounds are commonly identified in fruits, and have been revealed to scavenge free radicals through hydrogen or electron donation (26). Previous studies have demonstrated a positive association between phenolic functional groups and DPPH free radical scavenging activity (27).

Initially reported as a spontaneous murine mammary adenocarcinoma, the Ehrlich tumor may be grown in the majority of mouse strains and is accepted as a transplantable tumor model used to evaluate the anticancer effects of numerous substances (28). EAC, B-cell lymphoma proliferative diseases and chronic lymphocytic leukemia

diseases are all characterized by uncontrolled blood cell regulation; they require treatment with kinase enzyme inhibitors $(20,21)$. Kinase inhibitors bind to kinase proteins, whereas flavonoids bind to basic nucleosides in the presence of a nitrogenous base, to form an intermolecular bond with target protein kinases and inhibit cells from further growth (23). A rapid increase in ascetic tumor volume was revealed in EAC tumor-bearing mice, and treatment with Aponogeton undulatus extracts reduced the intraperitoneal tumor burden, thereby reducing tumor volume, tumor weight and viable cell count, in addition to increasing the lifespan of the tumor-bearing mice. Therefore, the increased lifespan of EAC-bearing mice in response to EAU treatment at $200 \mathrm{mg} / \mathrm{kg}$ may be due to a decrease in nutritional fluid volume and a delay in cell division, similar to the results of a previous study (22). Reductions in viable cell count and increases in non-viable cell counts towards normal levels in tumor hosts indicate anticancer effects against EAC cells in mice. These results suggest that EAU directly associates with cancer cells at high doses; they directly absorb the drug in the peritoneal cavity, resulting in cell lysis via a direct and cytotoxic mechanism (22). Anemia and myelo-suppression have frequently been observed in ascites carcinoma due to iron deficiency, either by hemolytic or myelopathic conditions, which eventually lead to reduced numbers of RBC (29). Treatment with EAU (100 mg/kg body weight, p.o.) returned the $\mathrm{Hb}$ content, $\mathrm{RBC}$ and $\mathrm{WBC}$ count to normal levels (Table III). These results provide support for EAU's hematopoietic protective effect, which occurs without inducing myelotoxicity, the most common side effect of cancer chemotherapy (23).

Plant-derived extracts with antioxidant potential have demonstrated cytotoxicity against cancer cells and anticancer activity in experimental animals (30). The cytotoxic and anticancer activity of plant-derived products occurs through the induction of apoptosis or the inhibition of neovascularization (31). In the present study, higher doses of EAU reduced cell growth and cancer cell viability, normalized hematological profiles and increased lifespan, compared with EAC control mice. EAU's ability to reduce lipid peroxidation and its free radical scavenging effects and reducing power indicate the potential use of Aponogeton undulatus extract as an inhibitor of intracellular free radicals induced by oxidative stress.

In conclusion, these novel results indicate that the Aponogeton undulatus leaf extract, in addition to its various organic fractions, has promising antioxidant properties and anticancer activity, as revealed by the in vivo studies. The next aim is to isolate and characterize the lead compounds that may be responsible for the aforementioned activity of Aponogeton undulatus. Furthermore, the identification of the ideal conditions for preserving Aponogeton undulatus samples, to minimize the damage to its antioxidant and biological properties following long-term storage, requires further study.

\section{Acknowledgements}

The present study was supported by the research fund from Chosun University, 2016. 


\section{References}

1. Duračková Z: Some current insights into oxidative stress. Physiol Res 59: 459-469, 2010.

2. Halliwell B: Free radicals, antioxidants, and human disease: Curiosity, cause, or consequence? Lancet 344: 721-724, 1994.

3. Poli G, Leonarduzzi G, Biasi F and Chiarpotto E: Oxidative stress and cell signalling. Curr Med Chem 11: 1163-1182, 2004.

4. Ames BN and Shigenaga MK: Oxidants are a major contributor to aginga. Ann N Y Acad Sci 663: 85-96, 1992.

5. Yeh CC, Hou MF, Tsai SM, Lin SK, Hsiao JK, Huang JC, Wang LH, Wu SH, Hou LA, Ma H and Tsai LY: Superoxide anion radical, lipid peroxides and antioxidant status in the blood of patients with breast cancer. Clin Chim Acta 361: 104-111, 2005.

6. Raskin I, Ribnicky DM, Komarnytsky S, Ilic N, Poulev A, Borisjuk N, Brinker A, Moreno DA, Ripoll C, Yakoby N, et al: Plants and human health in the twenty-first century. Trends Biotechnol 20: 522-531, 2002.

7. Branen AL: Toxicology and biochemistry of butylated hydroxyanisole and butylated hydroxytoluene. J Am Oil Chem Soc 52: 59-63, 1975 .

8. Watve A: Aponogeton undulatus. The IUCN Red List of Threatened Species, 2011.

9. Islam QR: Morphology and nutritional value of Aponogeton undulatus Roxb. growing in deeply flooded areas in Bangladesh. Hydrobiologia 340: 317, 1996.

10. Biswas SK and Ghosh SE: Bharotio Bonoushadhi. Vol 6. Calcutta University Press, India, 1977.

11. Chowdhury NS, Alam B, Tanbirul Haque ASM, Zahan R, Mazumder EH and Haque E: In vitro free radical scavenging and thrombolytic activities of Bangladeshi aquatic plant Aponogeton undulatus Roxb. Glob J Pharmacol 5: 27-32, 2011.

12. Yu L, Haley S, Perret J, Harris M, Wilson J and Qian M: Free radical scavenging properties of wheat extracts. J Agric Food Chem 50: 1619-1624, 2002.

13. Chang CC, Yang MH, Wen HM and Chern JC: Estimation of total flavonoid content in propolis by two complementary colorimetric methods. J food Drug Anal 10: 178-182, 2002.

14. Kumaran A and Karunakaran RJ: In vitro anti-oxidant activities of methanol extracts of Phyllanthus species from India. LWTFood Sci Technol 40: 344-352, 2007.

15. Prieto P, Pineda M and Aguilar M: Spectrophotometric quantitation of anti-oxidant capacity through the formation of a phosphomolybdenum complex: Specific application to the determination of vitamin E. Anal Biochem 269: 337-341, 1999.

16. Choi, Hong Yeob, Eun Ja Jhun, Beong Ou Lim, Ill Min Chung, Suk Hun Kyung and Dong Ki Park: Application of flow injection-chemiluminescence to the study of radical scavenging activity in plants. Phytotherapy Research 14: 250-253, 2000.

17. Liu F and Ng TB: Antioxidative and free radical scavenging activities of selected medicinal herbs. Life Sci 66: 725-735, 2000.
18. Oyaizu M: Studies on products of browning reactions. Antioxidative activities of products of browning reaction prepared from glucoseamine. Jpn J Nutr Diet 44: 307, 1986.

19. National Research Council: Guide for the Care and Use of Laboratory Animals. National Academies Press, Washington, DC, 1985.

20. Zahan R, Alam B, M Islam S, Sarker GC, Chowdhury NC, Hosain SB, Mosaddik MA, Jesmin M and Haque E: Activity of Alangium salvifolium flower in ehrlich ascites carcinoma bearing mice. Int J Cancer Res 7: 254-262, 2011.

21. Alam B, Sajid I, Rashid J, Islam M and Karmaker BK: Evaluation of antitumor effects of the aerial parts of polygonum viscosum linn. Glob J Pharmacol 8: 47-52, 2014.

22. Gupta M, Mazumder UK, Kumar RS, Sivakumar T and Vamsi ML: Antitumor activity and anti-oxidant status of Caesalpinia bonducella against Ehrlich ascites carcinoma in Swiss albino mice. J Pharmacol Sci 94: 177-184, 2004.

23. Sur P, Bag SP, Sur B and Khanam JA: Choroaceto hydroxamic acid as antitumor agent against Ehrlich ascites carcinoma in mice. Neoplasma 44: 197-201, 1997.

24. Packer L, Rimbach G and Virgili F: Antioxidant activity and biologic properties of a procyanidin-rich extract from pine (Pinus maritima) bark, pycnogenol. Free Radic Biol Med 27: 704-724, 1999.

25. Middleton E Jr, Kandaswami C and Theoharides TC: The effects of plant flavonoids on mammalian cells: Implications for inflammation, heart disease, and cancer. Pharmacol Rev 52: 673-751, 2000.

26. Shahidi F and Wanasundara PK: Phenolic anti-oxidants. Crit Rev Food Sci Nutr 32: 67-103, 1992.

27. Huang X, Dai J, Fournier J, Ali AM, Zhang Q and Frenkel K: Ferrous ion autoxidation and its chelation in iron-loaded human liver HepG2 cells. Free Radic Biol Med 32: 64-72, 2002.

28. Segura JA, Barbero LG and Márquez J: Ehrlich ascites tumor unbalances splenic cell populations and reduced responsiveness of T cells to Stapylococcus aureus enterotoxin B stimulation. Immunol Lett 74: 111-115, 2000.

29. Opare Kennedy D, Kojima A, Hasuma T, Yano Y, Otani S and Matsui-Yuasa I: Growth inhibitory effect of green tea extract and (-)-epigallocatechin in Ehrlich ascites tumor cells involves a cellular thiol-dependent activation of mitogenic-activated protein kinases. Chem Biol Interact 134: 113-133, 2001.

30. Ruby AJ, Kuttan G, Babu KD, Rajasekharan KN and Kuttan R: Anti-tumor and antioxidant activity of natural curcuminoids. Cancer Lett 94: 79-83, 1995.

31. Rakshit S, Mandal L, Pal BC, Bagchi J, Biswas N, Chaudhuri J, Chowdhury AA, Manna A, Chaudhuri U, Konar A, et al: Involvement of ROS in chlorogenic acid-induced apoptosis of Ber-Abl ${ }^{+}$CML cells. Biochem Pharmacol 80: 1662-1675, 2010. 